\title{
Nicotine, Cotinine, and Anabasine Inhibit Aromatase in Human Trophoblast In Vitro
}

Robert L. Barbieri, Jan Gochberg, and Kenneth J. Ryan

Laboratory of Human Reproduction and Reproductive Biology, Department of Obstetrics and Gynecology,

Brigham and Women's Hospital, Harvard Medical School, Boston, Massachusetts 02115

\section{Abstract}

Epidemiologic studies suggest that women who smoke have lower endogenous estrogen than nonsmokers. To explore the possible link between cigarette smoking and decreased endogenous estrogens, we have examined the effects of constituents of tobacco on estrogen production in human choriocarcinoma cells and term placental microsomes.

In choriocarcinoma cell cultures, nicotine, cotinine (a major metabolite of nicotine), and anabasine (a minor component of cigarette tobacco) all inhibited androstenedione conversion to estrogen in a dose-dependent fashion. Removal of nicotine, cotinine, and anabasine from the culture medium resulted in the complete reversal of the inhibition of aromatase. In the choriocarcinoma cell cultures, a supraphysiologic concentration of androstenedione $(73 \mu \mathrm{M})$ in the culture medium blocked the inhibition of aromatase caused by nicotine, cotinine, and anabasine.

In preparations of term placental microsomes, nicotine, cotinine, and anabasine inhibited the conversion of testosterone to estrogen. Kinetic analysis demonstrated the inhibition to be competitive with respect to the substrate. These findings suggest that some nicotinic alkaloids directly inhibit aromatase. This mechanism may explain, in part, the decreased estrogen observed in women who smoke.

\section{Introduction}

Recent epidemiologic evidence suggests that women who smoke have decreased endogenous estrogens (1). For example, endometrial cancer, which is thought to be an estrogen-dependent process, occurs less frequently in women who smoke than in nonsmokers (2). MacMahon et al. (3) have reported that in normally cycling women who smoke, urinary estrogens in the luteal phase of the cycle are lower than in nonsmokers. In pregnancy, women who smoke have lower estrogens than nonsmokers (4). Circumstantial evidence that women who smoke have disturbed endogenous estrogen production and/or metabolism is provided by epidemiologic studies which demonstrate that women who smoke have an earlier age of menopause $(5,6)$ and are at greater risk for postmenopausal osteoporosis $(7,8)$ than nonsmokers. To explore the possible link between cigarette smoking and decreased endogenous estrogens, we have examined the effects of

Address reprint requests to Dr. Barbieri, Laboratory of Human Reproduction, Harvard Medical School, 45 Shattuck St., Boston, MA 02115. Received for publication 10 December 1985.

J. Clin. Invest.

(C) The American Society for Clinical Investigation, Inc.

0021-9738/86/06/1727/07 \$1.00

Volume 77, June 1986, 1727-1733 constituents of tobacco on estrogen production in human choriocarcinoma cells and term placental microsomes.

\section{Methods}

Reagents. All radioactive materials were obtained from New England Nuclear (Boston, MA). RPMI 1640 and newborn calf serum were obtained from Gibco (Grand Island, NY). All other reagents were obtained from Sigma Chemical Co. (St. Louis, MO).

Jar choriocarcinoma cell cultures. Jar choriocarcinoma cells were obtained from Dr. R. A. Pattillo, Department of Obstetrics and Gynecology, The Medical College of Wisconsin, Milwaukee, WI (9). The feeder cell lines were cultured in plastic flasks in RPMI 1640 with $12 \%$ calf serum, $40 \mathrm{mM}$ glutamine, $100 \mathrm{U} / \mathrm{ml}$ penicillin, and $100 \mu \mathrm{g} / \mathrm{ml}$ streptomycin. Under these conditions, the cell number doubled every $2 \mathrm{~d}$.

Replicate cultures for experimentation were obtained by trypsinizing the cells in the feeder flasks and replating these cells at a density of $\sim 2.0$ $\times 10^{5}$ cells/well in a multiwell plate with a well diameter of $16 \mathrm{~mm}$. The cells were allowed to explant in the new wells for $16 \mathrm{~h}$ before experimentation. To begin all experiments the culture media were replaced with RPMI 1640 without serum, and the experimental agents were then added in a vehicle consisting of RPMI 1640. At the end of the experimental culture period the media were frozen, and the cells trypsinized and counted in a hemocytometer.

\section{Assessment of estrogen production in Jar choriocarcinoma cell cultures}

The media was extracted two times with 7 vol of ether. The ether extract was dried under a stream of $\mathrm{N}_{2}$, redissolved in isooctane, and applied to celite chromatography columns. Using isooctane and ethyl acetate as the mobile phase, progesterone, androstenedione, dihydrotestosterone, testosterone, estrone, and estradiol were sequentially eluted from the column $(10,11)$. Steroids were then measured using radioimmunoassays employing specific antibodies. Nicotine, cotinine, and anabasine did not interact with the antibodies used in the radioimmunoassays. Tritiated steroids were added to the samples just before ether extraction to assess recovery.

Placental microsomal preparations. Human term placentas were obtained at cesarean section. Placental microsomes were prepared as previously described (12). Microsomal protein concentration was measured using the method of Bradford (13).

\section{Assessment of aromatase activity in human term placental microsomes}

Aromatase activity was assessed in the placental microsomes by measuring the amount of ${ }^{3} \mathrm{H}_{2} \mathrm{O}$ formed due to the release of ${ }^{3} \mathrm{H}$ during the aromatization of $\left[1 \beta, 2 \beta-{ }^{3} \mathrm{H}\right]$ testosterone (14). The reaction mixture consisted of varying concentrations of $\left[1 \beta, 2 \beta-{ }^{3} \mathrm{H}\right]$ testosterone $(48.3 \mathrm{Ci} / \mathrm{mmol}$, sp act), $0.15 \mathrm{M} \mathrm{NaCl}, 10 \mathrm{mM} \mathrm{PO}_{4}$ buffer, $\mathrm{pH} 7.4$, at $37^{\circ} \mathrm{C}, 500 \mu \mathrm{M} \mathrm{NADPH}$, $50 \mathrm{mM}$ glucose-6-phosphate, and $10 \mathrm{U} / \mathrm{ml}$ of glucose-6-phosphate dehydrogenase, in a final volume of $0.5 \mathrm{ml}$. The reaction was started by adding the placental microsomes. The reactions were carried out in room air at $37^{\circ} \mathrm{C}$ in triplicate for 3 and 6 min to assess linearity of reaction velocity. The reaction was terminated by adding $0.6 \mathrm{ml}$ of dextran-coated charcoal. The charcoal-treated samples were incubated for $30 \mathrm{~min}$ and then centrifuged at $3,000 \mathrm{~g}$ for $10 \mathrm{~min}$. The quantity of ${ }^{3} \mathrm{H}_{2} \mathrm{O}$ in the aqueous supernatant was assessed by liquid scintillation counting. 
Assessment of 17ק-hydroxysteroid dehydrogenase activity in human term placental microsomes

$17 \beta$-Hydroxysteroid dehydrogenase was assayed as previously described (15). In brief, the reaction mixture consisted of $0.15 \mathrm{M} \mathrm{KCl}, 50 \mathrm{mM}$ Tris, pH 7.4, at $37^{\circ} \mathrm{C}, 500 \mu \mathrm{M}$ NADPH, $50 \mathrm{mM}$ glucose-6-phosphate, $5 \mathrm{U}$ glucose-6-phosphate dehydrogenase, $5 \mathrm{mM} \mathrm{MgCl}_{2}, \sim 0.5 \mu \mathrm{Ci}$ of $\left[6,7-{ }^{3} \mathrm{H}\right]$ estrone $(45 \mathrm{Ci} / \mathrm{mmol}$, sp act), $10 \mu \mathrm{g}$ placental microsomal protein, and various concentrations of nicotine in a final volume of $0.5 \mathrm{ml}$. The reaction mixture and the microsomal protein were preincubated separately at $37^{\circ} \mathrm{C}$. The reaction was started by the addition of $0.1 \mathrm{ml}$ of microsomal protein to the reaction mixture. Samples were incubated in duplicate for 3 and $6 \mathrm{~min}$ to verify linearity of reaction velocity. After incubation, the reaction was stopped by the addition of $0.5 \mathrm{ml}$ methanol. An aliquot of the reaction mixture was applied to silica gel thin-layer plates and product (estradiol) and substrate (estrone) were separated using a solvent system of ether/hexane $(3: 1, \mathrm{vol} / \mathrm{vol})$. The product and substrate were eluted from the gel and the radioactivity measured by liquid scintillation spectrometry. The authenticity of the product was established by high performance liquid chromatography.

\section{Preparation of smoke solutions}

Whole, aqueous cigarette smoke solutions were prepared as previously described (16). In brief, every minute, $35 \mathrm{ml}$ of tobacco smoke was drawn into a reservoir in a 2-s puff, until the cigarette butt was $5 \mathrm{~cm}$ in length. The smoke from two standard cigarettes was bubbled into $2 \mathrm{ml}$ of 0.01 $\mathrm{M}$ phosphate-buffered saline (PBS), $\mathrm{pH}$ 7.40. After the introduction of the smoke into the buffer the $\mathrm{pH}$ remained at 7.40. The aqueous solution was then passed through a $0.22-\mu \mathrm{M}$ filter to remove small particles.

In some experiments, the aqueous extracts were dialyzed against three changes of 200 vol PBS at $4^{\circ} \mathrm{C}$ using Spectra-Por 6 dialysis tubing ( 1,000 mol wt exclusion; Spectrum Medical Industries, Los Angeles, CA).

\section{Spectral determinations}

Spectral determinations were made, as previously described (17), using a DW-2 UV-visible spectrophotometer (American Instrument Co., Silver Spring, MD). Cytochrome P-450 concentrations were measured by the method of Estabrook (18) using an extinction coefficient of 100 $\mathrm{mM}^{-1} \cdot \mathrm{cm}^{-1}$ for the absorption difference at $450 \mathrm{~nm}$ minus $500 \mathrm{~nm}$. To determine the spectral changes caused by the addition of experimental compounds to the microsomal preparations, $2 \mathrm{ml}$ of a microsomal suspension was divided between sample and reference cuvettes, and a baseline of equal light absorbance was obtained. The experimental compound, dissolved in ethanol, was added to the sample cuvette and an equal concentration of ethanol was added to the reference cuvette. The ethanol concentration in the cuvettes never exceeded $1.0 \%$ (vol/vol).

Screening for estradiol and progesterone metabolism in the Jar choriocarcinoma cell cultures using high performance liquid chromatography

The hardware consisted of a Waters Assoc. (Milford, MA) 680-gradient controller, two 510 solvent pumps, a UK6 injector, a $\mathrm{C}_{18-\mu \text { Bondapak }}$ column, and a fraction collector. To screen for the metabolism of estradiol, $1 \mu \mathrm{Ci}$ of $\left[6,7-{ }^{3} \mathrm{H}\right]$ estradiol $(45 \mathrm{Ci} / \mathrm{mmol}$, sp act) was added to a culture containing $2 \times 10^{5}$ choriocarcinoma cells for $24 \mathrm{~h}$. The steroids in the medium plus cells were ether extracted. The ether extract was filtered, applied to the column, and the steroids were eluted with methanol and water $(50: 50, \mathrm{vol} / \mathrm{vol})$. To screen for the metabolism of progesterone, $1 \mu \mathrm{Ci}$ of $\left[1,2-{ }^{3} \mathrm{H}\right]$ progesterone $(42 \mathrm{Ci} / \mathrm{mmol}$, sp act) was added to a culture containing $2 \times 10^{5}$ choriocarcinoma cells for $24 \mathrm{~h}$. The ether-extracted, filtered steroids were applied to the column and eluted with methanol and water $(65: 35, \mathrm{vol} / \mathrm{vol})$.

\section{Results}

\section{Characterization of Jar choriocarcinoma cell cultures}

During the first $48 \mathrm{~h}$ of cell culture, estradiol and progesterone accumulation were linear over time and cell number $\left(2.5 \times 10^{4}-\right.$
$2.5 \times 10^{5}$ cells/well). In serum-free choriocarcinoma cell cultures, estradiol and estrone were not detectable $(<0.05 \mathrm{pmol} / \mathrm{ml})$ unless androgen substrate (androstenedione or testosterone) was added to the medium. Androstenedione in concentrations as low as 2 $\mathrm{nM}$ resulted in the significant accumulation of estradiol. Maximal estradiol accumulation occurred at androstenedione concentrations between $400 \mathrm{nM}$ and $1 \mu \mathrm{M}$. In women, androstenedione concentrations in the circulation ranged between $0.3 \mathrm{nM}$ and $11 \mathrm{nM}$. Therefore, in most incubations the androstenedione concentration used was $11 \mathrm{nM}$ (19). Progesterone and estradiol were not rapidly metabolized by the choriocarcinoma cells. Addition of $1 \mu \mathrm{Ci}$ of $\left[1,2-{ }^{3} \mathrm{H}\right]$ progesterone or $\left[6,7-{ }^{3} \mathrm{H}\right]$ estradiol to $2 \times 10^{5}$ choriocarcinoma cells for $24 \mathrm{~h}$ resulted in the conversion of $<15 \%$ of the progesterone and $<10 \%$ of the estradiol to other metabolites as determined by high performance liquid chromatography. Using radioactive progesterone and estradiol, partitioning experiments demonstrated that $95 \%$ of these two steroids were present in the culture medium and $<5 \%$ in the explanted cells. These results suggest that progesterone and estradiol accumulation in the media correlate well with production.

Addition of androstenedione to the choriocarcinoma cultures resulted in the appearance of both estradiol and estrone, but not testosterone or dihydrotestosterone. For example, the addition of $18 \mathrm{nM}$ androstenedione to 200,000 choriocarcinoma cells for $18 \mathrm{~h}$ resulted in the detection of $12.6 \mathrm{nM}$ estradiol, $1.26 \mathrm{nM}$ estrone, $25.3 \mathrm{nM}$ progesterone, and $<0.2 \mathrm{nM}$ testosterone and dihydrotestosterone in the media at the end of the incubation (Table I). In all experiments the accumulation of estradiol always exceeded the accumulation of estrone, and the ratio of estradiol to estrone was in the range of $6: 1-10: 1$.

\section{Effects of aqueous extracts of cigarette smoke on estrogen accumulation in choriocarcinoma cell cultures}

Aqueous extracts of smoke inhibited androstenedione conversion to estradiol in a dose-dependent manner (Fig. $1 A$ ). $50 \%$ inhibition of aromatase was observed at a smoke extract dose between 1 and $5 \mu \mathrm{l}(1 \mu \mathrm{l}$ of aqueous smoke solution represents $0.1 \%$ of a cigarette equivalent). At the doses used in this study, aqueous extracts of cigarette smoke did not inhibit progesterone accumulation or the cell number present in the culture. The PBS vehicle, in doses up to $30 \mu \mathrm{l}$, did not affect estradiol accumulation. Dialyzed smoke preparations $(1,000 \mathrm{~mol} \mathrm{wt}$ effective pore size) inhibited androstenedione conversion to estradiol in a dosedependent manner (Fig. $1 \mathrm{~B}$ ). At the highest dose tested, $25 \mu$, aromatization was inhibited by $40 \%$. Therefore, $\sim 10 \%$ of the aromatase inhibitory activity of aqueous extracts of cigarette smoke was present in the $>1,000$-mol-wt fraction. Removal of the aqueous extract of cigarette smoke from the culture medium resulted in the complete reversal of the inhibition of aromatase, and the return of normal rates of aromatization.

\section{Effects of nicotine, cotinine, and anabasine on estrogen accumulation in choriocarcinoma cell cultures}

The addition of nicotine, cotinine, or anabasine to the choriocarcinoma cell cultures inhibited estradiol accumulation in the media (Fig. 2). The addition of nicotine to the choriocarcinoma cell cultures resulted in the inhibition of both estradiol and estrone accumulation and a corresponding increase in unmetabolized androstenedione (Table I). At all nicotine concentrations tested, the estradiol to estrone ratio exceeded 6:1. 50\% inhibition of estradiol accumulation was observed at nicotine, cotinine, and anabasine concentrations of $\sim 30,30$, and $4 \mu \mathrm{M}$, respec- 
Table I. Effects of Nicotine on Androstenedione, Estradiol, Estrone, Testosterone, Dihydrotestosterone, and Progesterone Accumulation in Choriocarcinoma Cell Cultures

\begin{tabular}{|c|c|c|c|c|c|c|}
\hline $\begin{array}{l}\text { Nicotine } \\
\text { concentration }\end{array}$ & Androstenedione & Estradiol & Estrone & Testosterone & Dihydrotestosterone & Progesterone \\
\hline$\mu M$ & $\mathrm{pmol} / \mathrm{ml}$ & $\mathrm{pmol} / \mathrm{ml}$ & $\mathrm{pmol} / \mathrm{ml}$ & $\mathrm{pmol} / \mathrm{ml}$ & $\mathrm{pmol} / \mathrm{ml}$ & $\mathrm{pmol} / \mathrm{ml}$ \\
\hline 0 & $4.51 \pm 0.57$ & $12.6 \pm 1.39$ & $1.26 \pm 0.29$ & $<0.2$ & $<0.2$ & $25.3 \pm 4.68$ \\
\hline 1 & $5.21 \pm 0.41$ & $11.2 \pm 0.88$ & $1.15 \pm 0.42$ & $<0.2$ & $<0.2$ & $26.8 \pm 2.04$ \\
\hline 5 & $7.88 \pm 0.46$ & $7.58 \pm 0.79^{*}$ & $1.05 \pm 0.12$ & $<0.2$ & $<0.2$ & $32.2 \pm 2.37$ \\
\hline 30 & $11.2 \pm 0.78$ & $5.69 \pm 0.46^{*}$ & $0.93 \pm 0.49$ & $<0.2$ & $<0.2$ & $31.2 \pm 2.03$ \\
\hline 150 & $12.4 \pm 0.90$ & $2.66 \pm 0.44^{*}$ & $0.36 \pm 0.12^{*}$ & $<0.2$ & $<0.2$ & $30.8 \pm 3.4$ \\
\hline
\end{tabular}

$2.0 \times 10^{5}$ choriocarcinoma cells were cultured for $18 \mathrm{~h}$ in serum-free RPMI 1640 containing $18 \mathrm{pmol} / \mathrm{ml}$ of androstenedione with varying concentrations of nicotine. Mean $\pm \mathrm{SEM}, n=4$. $^{*} P<0.01$ compared with vehicle-treated group.

tively. At concentrations up to $30 \mu \mathrm{M}$ these three compounds did not inhibit progesterone accumulation (Fig. 2). 150- $\mu \mathrm{M}$ concentrations of both anabasine and nicotine resulted in a decrease in progesterone accumulation of $\sim 15 \%$ (Fig. 2). At concentrations up to $150 \mu \mathrm{M}$, nicotine, cotinine, and anabasine did not alter cell number at the end of an 8-h incubation. Removal of nicotine, cotinine, and anabasine from the culture medium resulted in the complete reversal of the inhibition of estradiol accumulation and the return to normal rates of estradiol accumulation. The data for the reversibility of nicotine inhibition of estradiol accumulation is presented in Table II.

Examination of the timecourse of nicotine inhibition of estradiol accumulation demonstrated that nicotine inhibited estradiol accumulation at the first timepoint examined, $1 \mathrm{~h}$ (Fig. 3). Nicotine inhibition of estradiol accumulation was linear over the first $8 \mathrm{~h}$ of incubation (Fig. 3).

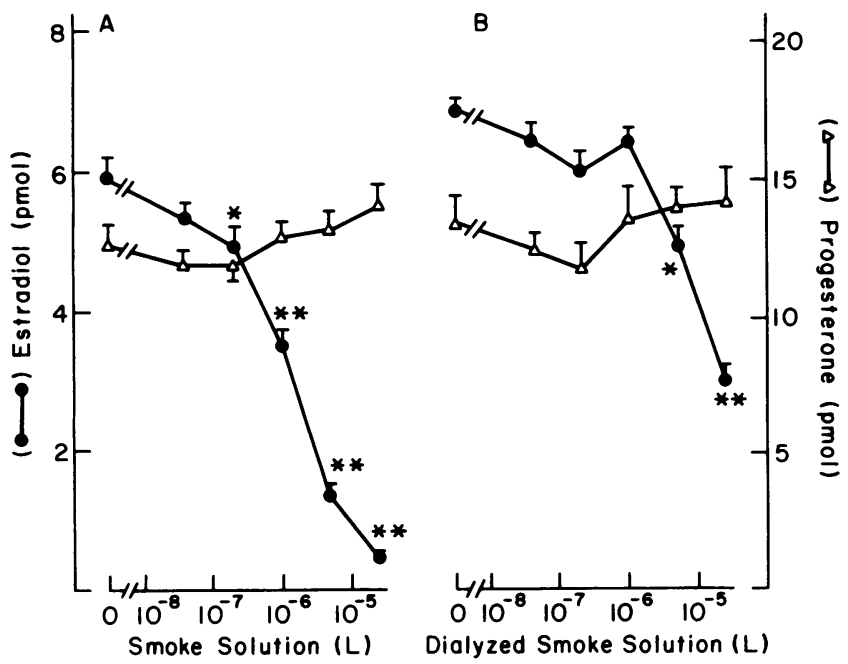

Figure 1. Effects of smoke solution and dialyzed (1,000 mol wt cutoff) smoke solution on estrogen and progesterone accumulation in choriocarcinoma cell cultures. $2.0 \times 10^{5}$ choriocarcinoma cells were cultured for $8 \mathrm{~h}$ in serum-free RPMI 1640 containing $11 \mathrm{nM}$ androstenedione and various concentrations of smoke solution. At the end of the incubation, the media was assayed for estradiol, estrone, and progesterone. The estrone accumulation was $<17 \%$ of the estradiol accumulation at all points. $1 \mu \mathrm{l}$ smoke represents $0.1 \%$ of a cigarette equivalent. The vehicle containing the smoke solution was $0.01 \mathrm{M}$ phosphate-buffered saline. At the highest doses used $(30 \mu \mathrm{l})$, the vehicle alone did not alter estrogen accumulation. Mean $\pm \mathrm{SEM}, n=4$ for each group. ${ }^{*} P<0.01$; ${ }^{* *} P<0.0001$ compared with vehicle control.
In addition to inhibiting estradiol accumulation in intact choriocarcinoma cell cultures, nicotine also inhibited estradiol accumulation in cell-free preparations of choriocarcinoma cells. Choriocarcinoma cells were sonicated in serum-free RPMI 1640 until no intact cells could be demonstrated by microscopic examination. Aliquots of the cell-free suspension equivalent to 2.0 $\times 10^{5}$ choriocarcinoma cells were incubated with $11 \mathrm{nM}$ androstenedione and varying concentrations of nicotine. Nicotine inhibited the accumulation of estradiol in a manner comparable to that observed in incubations of intact cells (data not shown).

In the choriocarcinoma cell cultures, the concentration of androstenedione present in the culture medium strongly influenced the degree of inhibition of estradiol accumulation produced by nicotine. For example, when the culture medium contained $11 \mathrm{nM}$ androstenedione, $30 \mu \mathrm{M}$ nicotine produced an $\sim 50 \%$ inhibition of estradiol accumulation. In contrast, when the culture medium contained $73 \mu \mathrm{M}$ androstenedione, $30 \mu \mathrm{M}$ nicotine produced no inhibition of estradiol accumulation (Fig. 4).

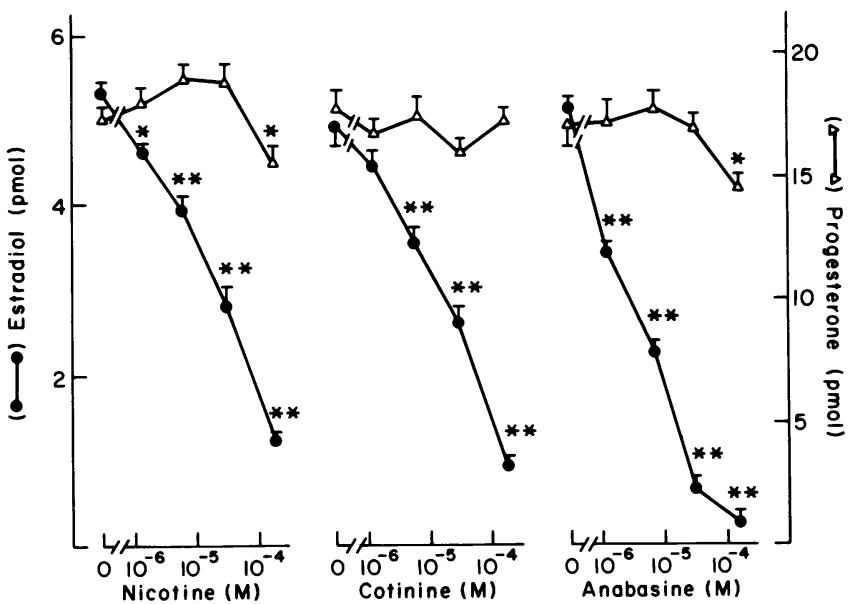

Figure 2. Effects of nicotine, cotinine, and anabasine on estrogen and progesterone accumulation in choriocarcinoma cell cultures. $2.0 \times 10^{5}$ choriocarcinoma cells were cultured for $8 \mathrm{~h}$ in serum-free RPMI 1640 with $11 \mathrm{nM}$ androstenedione and various concentrations of the experimental agents. At the end of the incubation, the media was assayed for progesterone, estradiol, and estrone. The estrone accumulation was $<17 \%$ of the estradiol accumulation at all points. Mean \pm SEM, $n=4$ for each group. ${ }^{*} P<0.01 ;{ }^{* *} P<0.0001$ compared with vehicle control. 
Table II. Reversibility of Nicotine Inhibition of Estrogen Accumulation in Choriocarcinoma Cell Cultures

\begin{tabular}{lcclll}
\hline & Treatment 1 & Treatment 2 & & \multicolumn{2}{l}{ Estradiol accumulation } \\
\cline { 2 - 3 } \cline { 5 - 6 } Group & \multicolumn{2}{c}{ Nicotine concentration } & & $0-12 \mathrm{~h}$ & $12-24 \mathrm{~h}$ \\
\hline & $\mu M$ & $\mu M$ & & $p m o l$ & $p m o l$ \\
A & 0 & 0 & & $6.52 \pm 0.11$ & $6.26 \pm 0.19$ \\
B & 1.25 & 0 & & $5.86 \pm 0.04^{*}$ & $6.73 \pm 0.25 \ddagger$ \\
C & 6 & 0 & & $4.59 \pm 0.17^{*}$ & $6.55 \pm 0.06 \ddagger$ \\
D & 30 & 0 & & $3.25 \pm 0.12^{*}$ & $6.55 \pm 0.10 \ddagger$ \\
E & 150 & 0 & & $1.05 \pm 0.06^{*}$ & $6.80 \pm 0.24 \ddagger$ \\
F & 30 & 30 & & $3.32 \pm 0.10^{*}$ & $2.85 \pm 0.05^{*}$ \\
G & 150 & 150 & & $1.08 \pm 0.04^{*}$ & $0.97 \pm 0.06^{*}$
\end{tabular}

At "time 0" cells were treated with nicotine or vehicle (treatment 1). After $12 \mathrm{~h}$ of treatment the culture medium was changed, the culture wells were washed with fresh medium, and new medium without nicotine was added, except for groups $F$ and $G$ where new nicotine was added (treatment 2). The androstenedione concentration of the medium was $11 \mathrm{nM}$. Mean \pm SEM, $n=4$.

$* P<0.01$.

$\ddagger$ Not significantly different compared with group A.

As noted above, nicotine, cotinine, and anabasine all inhibited estradiol accumulation in choriocarcinoma cells at micromolar concentrations. In contrast, at concentrations in the range of $1 \mathrm{mM}$, carbamylcholine, succinylcholine, hexamethonium, and decamethonium did not inhibit estradiol accumulation (Table III).

\section{Effects of nicotine, anabasine, and cotinine on aromatase activity in preparations of term placental microsomes}

In term placental microsomes the apparent maximum velocity $V_{\max }$ for the conversion of $\left[1 \beta, 2 \beta-{ }^{3} \mathrm{H}\right]$ testosterone to estrogen as determined by the ${ }^{3} \mathrm{H}_{2} \mathrm{O}$ assay was $49.5 \pm 8.7 \mathrm{pmol} / \mathrm{min}$ per $\mathrm{mg}$ microsomal protein (mean \pm SEM, based on placental preparations from 10 women). The apparent Michaelis-Menton constant $\left(K_{\mathrm{m}}\right)$ for the aromatization of $\left[1 \beta, 2 \beta-{ }^{3} \mathrm{H}\right]$ testosterone to estrogen was $23 \pm 2.1 \mathrm{nM}$ (mean $\pm \mathrm{SEM}$, based on placental preparations

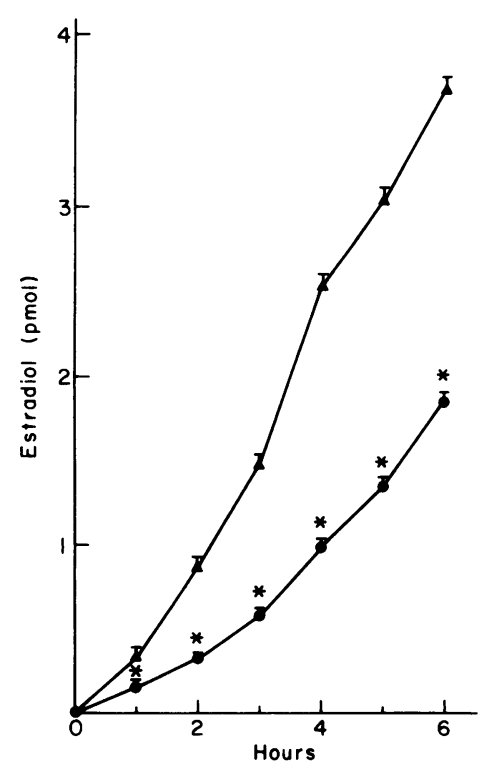

Figure 3. Time course of nicotine inhibition of estrogen accumulation in choriocarcinoma cell cultures. 2.0 $\times 10^{5}$ choriocarcinoma cells were cultured in serum-free RPMI 1640 containing 11 $\mathrm{nM}$ androstenedione in the absence of nicotine $(\Delta)$ or in the presence of $30 \mu \mathrm{M}$ nicotine (๑). At each time period the media was assayed for estradiol, estrone, and progesterone. At all points the estrone accumulation was $<17 \%$ of the estradiol accumulation. The progesterone accumulation was unaffected by $30 \mu \mathrm{M}$ nicotine. Mean \pm SEM, $n=8$ for each group. ${ }^{*} P<0.0001$ compared with vehicle control.

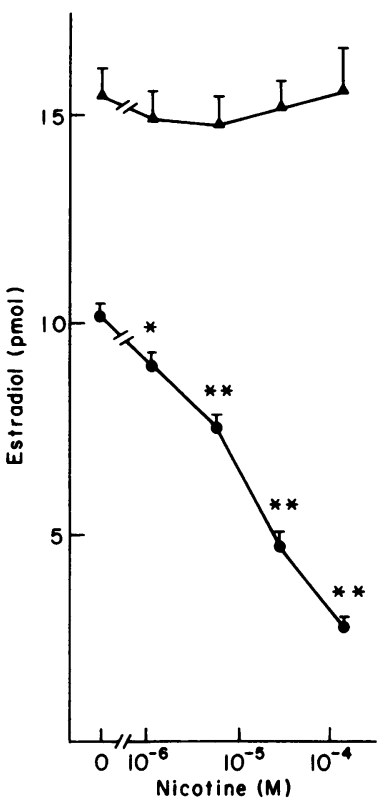

Figure 4. Effect of androstenedione concentration on nicotine inhibition of estrogen accumulation in choriocarcinoma cell cultures. 2.0 $\times 10^{5}$ choriocarcinoma cells were cultured for $18 \mathrm{~h}$ in serum-free RPMI 1640 with either $11 \mathrm{nM}$ androstenedione (•) or $73 \mu \mathrm{M}$ androstenedione $(\Delta)$. At the end of the incubation the media was assayed for estradiol, estrone, and progesterone. The estrone accumulation was $<17 \%$ of the estradiol accumulation at all points. Changes in nicotine and androstenedione concentration did not alter progesterone accumulation. Mean \pm SEM, $n=4$ for each group. ${ }^{*} P<0.01 ;{ }^{* *} P$ $<0.0001$ compared with vehicle control.

from 10 women). These values are similar to those previously reported (17).

In all preparations of placental microsomes examined, nicotine, cotinine, and anabasine inhibited the conversion of $[1 \beta, 2 \beta-$ ${ }^{3} \mathrm{H}$ ] testosterone to ${ }^{3} \mathrm{H}_{2} \mathrm{O}$. Dixon plot analysis demonstrated that nicotine, cotinine, and anabasine inhibition of aromatase was competitive with respect to the testosterone substrate (Figs. 5 and 6). The effects of nicotine on aromatase in placental microsomes was assessed in tissue obtained from five women. In these five separate experiments the apparent enzymatic inhibition constants $\left(K_{\mathrm{i}}\right)^{1}$ for nicotine inhibition of aromatization were 15 , $17,25,37$, and $73 \mu \mathrm{M}(33 \pm 10.6 \mu \mathrm{M}$, mean \pm SEM) (Fig. 5). The effects of cotinine on aromatase in placental microsomes was assessed in tissue obtained from three women. In these three separate experiments the $K_{\mathrm{i}} \mathrm{s}$ for cotinine inhibition of aromatization were 15,36 , and $47 \mu \mathrm{M}(32.7 \pm 9.38 \mu \mathrm{M}$, mean $\pm \mathrm{SEM})$ (Fig. 6). The effects of anabasine on aromatase in placental microsomes was assessed in tissue obtained from two women. In these two experiments the apparent $K_{\mathrm{i}} \mathrm{s}$ for anabasine inhibition of aromatase were 2 and $3 \mu \mathrm{M}$.

In contrast to nicotine, cotinine, and anabasine, the cholinergic agents-hexamethonium, decamethonium, acetylcholine, succinylcholine, carbamylcholine, and muscarine-did not inhibit aromatase in the placental microsomes (Table IV). Lobeline, at concentrations of $100 \mu \mathrm{M}$, produced a $30 \%$ inhibition of placental microsomal aromatase.

\section{Effects of nicotine on $17 \beta$-hydroxysteroid dehydrogenase activity in term placental microsomes}

Nicotine, at concentrations as high as $100 \mu \mathrm{M}$, did not significantly alter placental microsomal $17 \beta$-hydroxysteroid dehydrogenase activity (Table V).

\section{Spectral analysis of nicotine interaction with placental} microsomal cytochrome P-450

In the preparations of placental microsomes, the concentration of cytochrome P-450 ranged from 0.04 to $0.055 \mathrm{nmol} / \mathrm{mg} \mathrm{mi-}$

1. Abbreviation used in this paper: $K_{\mathrm{i}}$, enzymatic inhibition constant(s). 
Table III. Effects of Nicotine, Carbamylcholine, Succinylcholine, Hexamethonium, and Decamethonium on Estradiol Accumulation in Cultures of Choriocarcinoma Cells

\begin{tabular}{lcl}
\hline Compound & Concentration & Estradiol \\
\hline & & $p m o l / m l$ \\
Vehicle (RPMI 1640) & - & $5.58 \pm 0.52$ \\
Nicotine & $50 \mu \mathrm{M}$ & $1.40 \pm 0.11^{*}$ \\
& $150 \mu \mathrm{M}$ & $0.59 \pm 0.05^{*}$ \\
Carbamylcholine & $1.2 \mathrm{mM}$ & $5.16 \pm 0.17 \ddagger$ \\
& $6.0 \mathrm{mM}$ & $5.71 \pm 0.17 \ddagger$ \\
Succinylcholine & $0.3 \mathrm{mM}$ & $5.71 \pm 0.17 \ddagger$ \\
& $1.5 \mathrm{mM}$ & $5.30 \pm 0.16 \ddagger$ \\
Hexamethonium & $0.3 \mathrm{mM}$ & $6.06 \pm 0.20 \ddagger$ \\
& $1.5 \mathrm{mM}$ & $4.84 \pm 0.41 \ddagger$ \\
Decamethonium & $0.3 \mathrm{mM}$ & $5.00 \pm 0.19 \ddagger$ \\
& $1.5 \mathrm{mM}$ & $5.24 \pm 0.24 \ddagger$
\end{tabular}

$2.0 \times 10^{5}$ choriocarcinoma cells per well were cultured in serum-free RPMI 1640 with $11 \mathrm{nM}$ androstenedione and the experimental compounds for $8 \mathrm{~h}$. Mean \pm SEM, $n=4$.

$* P<0.01$ compared with vehicle.

$¥$ Not significantly different than vehicle.

crosomal protein. Addition of nicotine to placental microsomal preparations elicited a type II cytochrome P-450 difference spectrum with a broad Soret minimum between 390 and $400 \mathrm{~nm}$ and a Soret maximum at $428 \mathrm{~nm}$ (Fig. 7).

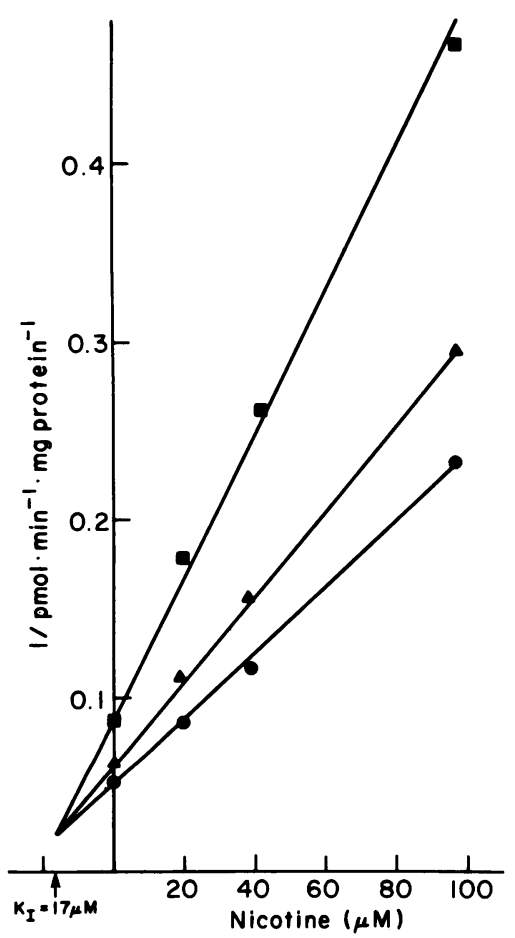

Figure 5. Dixon plot of nicotine inhibition of aromatase activity in human placental microsomes. Substrate: $\left[1 \beta, 2 \beta-{ }^{3} \mathrm{H}\right]$ testosterone. Substrate concentrations: $\mathrm{n}, 4.90 \mathrm{nM} ; \triangle, 7.40 \mathrm{nM}$; and $\bullet, 12.5 \mathrm{nM}$. Product: ${ }^{3} \mathrm{H}_{2} \mathrm{O}$. Microsomal protein concentration: $72 \mu \mathrm{g} / \mathrm{ml}$. Incubation time: $\mathbf{3} \min . n=3$ for each point.

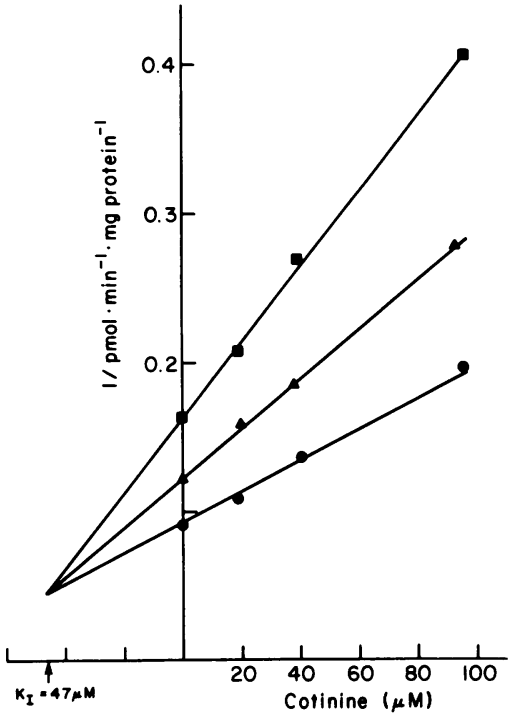

Figure 6. Dixon plot of cotinine inhibition of aromatase activity in human placental microsomes. Substrate: $\left[1 \beta, 2 \beta-{ }^{3} \mathrm{H}\right]$ testosterone. Substrate concentrations: $₫, 4.67 \mathrm{nM} ; \triangle, 6.69 \mathrm{nM}$; and $\bullet, 9.68 \mathrm{nM}$. Product: ${ }^{3} \mathrm{H}_{2} \mathrm{O}$. Microsomal protein concentration: $31 \mu \mathrm{g} / \mathrm{ml}$. Incubation time: 3 min. $n=3$ for each point.

\section{Discussion}

In both the choriocarcinoma cell cultures and placental microsomes, micromolar concentrations of nicotine, cotinine, and anabasine inhibited estrogen formation. It is unlikely that the nicotine inhibition of estradiol accumulation observed in the choriocarcinoma cell cultures is due to a "nonspecific" detrimental effect on cell function. Evidence to suggest that nicotine inhibition of estradiol accumulation was due to a highly specific mechanism includes the following observations: (a) No change in progesterone accumulation or cell number was observed at nicotine concentrations that produced $50 \%$ inhibition of estradiol accumulation; $(b)$ The nicotine inhibition of estradiol accumulation was completely reversible by removing the nicotine

Table IV. Effects of Various Agents on Human Placental Microsomal Aromatase

\begin{tabular}{lll}
\hline & Concentration & Estrogen production \\
\hline & $m M$ & pmol/min per $m g$ protein \\
Vehicle & 0 & 20.3 \\
Nicotine & 0.1 & 2.2 \\
Cotinine & 0.1 & 2.1 \\
Nicotine sulfate & 0.5 & 0.04 \\
Anabasine & 0.1 & 0.05 \\
Hexamethonium & 2.2 & 18.4 \\
Decamethonium & 1.9 & 18.2 \\
Succinylcholine & 2.2 & 19.4 \\
Acetylcholine & 4.4 & 20.3 \\
Carbamylcholine & 3.8 & 20.0 \\
Muscarine & 4.4 & 16.1 \\
\end{tabular}

Substrate: $\left[1 \beta, 2 \beta-{ }^{3} \mathrm{H}\right]$ testosterone. Product: ${ }^{3} \mathrm{H}_{2} \mathrm{O}$. Substrate concentration: $10.1 \mathrm{nM}$. Microsomal protein concentration: $30 \mu \mathrm{g} / 0.5 \mathrm{ml}$. Incubation time: $3 \mathrm{~min}$. 
Table V. Effects of Nicotine on Human Placental Microsomal 17ß-Hydroxysteroid Dehydrogenase

\begin{tabular}{cl}
\hline $\begin{array}{l}\text { Nicotine } \\
\text { concentration }\end{array}$ & Estradiol production \\
\hline$\mu M$ & pmol/min per $\mathrm{mg}$ protein \\
0 & 89.8 \\
10 & 99.3 \\
100 & 92.4
\end{tabular}

Substrate: $\left[6,7-{ }^{3} \mathrm{H}\right]$ estrone. Product: $\left[{ }^{3} \mathrm{H}\right]$ estradiol. Substrate concentration: $23 \mathrm{nM}$. Microsomal protein concentration: $10 \mu \mathrm{cg} / 0.5 \mathrm{ml}$. Incubation time: $3 \mathrm{~min}$.

from the culture medium; and (c) Supraphysiologic concentrations of androstenedione $(73 \mu \mathrm{M})$ completely blocked the nicotine inhibition of estradiol accumulation. The biochemical mechanism responsible for the nicotine inhibition of estradiol accumulation in the choriocarcinoma cell cultures is unclear. However, the experiments examining the effects of nicotine on aromatase in term placental microsomes suggests that nicotine directly inhibits the choriocarcinoma cell aromatase enzyme system.

In term placental microsomes, micromolar concentrations of nicotine, cotinine, and anabasine competitively inhibited the aromatization of testosterone. This finding, in conjunction with the spectral evidence that nicotine interacted directly with placental microsomal cytochrome P-450, suggests that nicotine may inhibit placental aromatase by reversibly altering the function of the active site(s) of the cytochrome P-450 component of the aromatase enzyme system.

Aminoglutethimide is an inhibitor of aromatase that is used clinically in the hormonal therapy of metastatic breast cancer. In placental microsomal preparations, aminoglutethimide competitively inhibits the aromatization of testosterone with an apparent $K_{\mathrm{i}}$ of $14 \mu \mathrm{M}(20)$. The addition of aminoglutethimide to preparations of placental microsomes elicits a type II cytochrome P-450 binding spectrum (20). Given these functional similarities between aminoglutethimide and nicotine, it is of interest to note that nicotine, cotinine, anabasine, and aminoglutethimide all share substantial chemical structural similarities. In addition to cigarette tobacco, other plants contain compounds that can in-

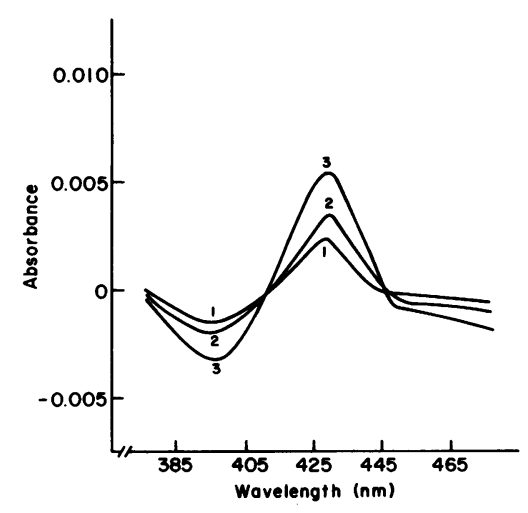

Figure 7. Nicotine binding to human placental microsomal cytochrome P-450. Concentration of nicotine: (1) $25 \mu \mathrm{M}$; (2) $50 \mu \mathrm{M}$; and (3) $100 \mu \mathrm{M}$. Cuvette volume: $1 \mathrm{ml}$. Microsomal protein concentration: $4 \mathrm{mg} / \mathrm{ml}$. hibit placental aromatase. For example, Kellis and Vickery have reported that naturally occurring plant flavones are potent inhibitors of aromatase (21). Function-structure analysis of the specific chemical properties of the nicotinic alkaloids and the flavones that mediate the inhibition of aromatase may suggest new chemical structures that could serve as clinically useful inhibitors of this important enzyme system.

In nonpregnant women who smoke, plasma nicotine and cotinine concentrations are in the range of 0.25 and $2 \mu \mathrm{M}$, respectively (22-24). In other body fluids and tissues the concentration of nicotine may be much higher. For example, salivary nicotine concentrations of $1 \mu \mathrm{M}(25)$ and cervical mucus nicotine concentrations of $10 \mu \mathrm{M}$ have been reported (26). Nicotine concentrations in the hair of smokers has been reported to be 100 $\mu \mathrm{M}(27,28)$. In pregnant women the cotinine concentration in the fetal circulation is 2-4-fold higher than the cotinine concentration in the maternal circulation (4). We are unaware of published studies reporting the concentration of anabasine in body fluids or tissues of smokers. The nicotine and cotinine concentrations present in ovarian follicular fluid and in steroidogenic tissues of women who smoke have not been reported. However, the concentrations of nicotine and cotinine that have been reported to be present in the body fluids of women who smoke suggests that the in vitro findings reported here may have relevance in vivo.

MacMahon et al. (3) have reported that normally cycling women who smoke have decreased urinary estrogens in the luteal phase of the menstrual cycle, but not during the follicular phase. If the granulosa cell and placental aromatase are similar, then the in vitro observation that nicotine and cotinine "competitively" inhibit placental aromatase could explain these findings. In the follicular phase of the menstrual cycle, the ovarian follicle that gains dominance produces the majority of circulating estrogens (29). A characteristic of the dominant ovarian follicle is that a restricted follicular microenvironment is present. The follicular microenvironment consists of those elements on the avascular side of the follicular basement membrane: $(a)$ granulosa cells, $(b)$ antral fluid, and $(c)$ oocyte. In the follicular phase of the menstrual cycle, the circulating androstenedione concentration is $\sim 5 \mathrm{nM}$. However, the intrafollicular concentration of androstenedione is $\sim 500$ times greater, $2.5 \mu \mathrm{M}(30)$. The aromatase enzyme system in the granulosa cell is probably exposed to the intrafollicular concentration of androstenedione, $2.5 \mu \mathrm{M}$. If the intrafollicular concentration of nicotine plus cotinine were $5 \mu \mathrm{M}$, the ratio of nicotine plus cotinine to androstenedione would be $2: 1$. This ratio is too low to produce significant inhibition. In contrast, in the luteal phase of the menstrual cycle, the basement membrane of the dominant follicle is disrupted, and the follicular microenvironment is lost. The aromatase enzyme system in the cells comprising the corpus luteum is probably exposed to an androstenedione concentration similar to that in the circulation, $5 \mathrm{nM}$. If the corpus luteum is exposed to a nicotine plus cotinine concentration of $5 \mu \mathrm{M}$, then the ratio of nicotine plus cotinine to androstenedione would be 1,000:1. This high ratio could produce significant inhibition of the aromatase system and a decrease in estrogen production.

In postmenopausal women, circulating androstenedione concentrations less than $2 \mathrm{nM}$ are common (18). Therefore, in postmenopausal women, the ratio of nicotine plus cotinine to androstenedione at the peripheral aromatase site may be greater than 1,000 to 1 . These considerations suggest that postmenopausal women may be especially sensitive to the effects of nic- 
otine and cotinine on estrogen production. Jensen et al. have recently reported that in postmenopausal women, smoking may increase the metabolic clearance rate of estradiol (31). To determine the relative quantitative effects of smoking on estrogen production versus metabolism will require sophisticated in vivo radiotracer studies.

\section{Acknowledgments}

This work was supported in part by grant HD-18292 from the National Institutes of Health.

\section{References}

1. Baron, J. A. 1984. Smoking and estrogen-related disease. Am. J. Epidemiol. 119:9-22.

2. Lesko, S. M., L. Rosenberg, D. W. Kaufman, S. P. Helmrich, D. R. Miller, B. Strom, D. Schottenfeld, N. B. Rosenshein, R. C. Knapp, J. Lewis, and S. Shapiro. 1985. Cigarette smoking and the risk of endometrial cancer. N. Engl. J. Med. 313:593-596.

3. MacMahon, B., D. Trichopoulos, P. Cole, and J. Brown. 1982. Cigarette smoking and urinary estrogens. N. Engl. J. Med. 307:10621065.

4. Mochizuki, M., T. Maruo, K. Masuko, and T. Ohtsu. 1984. Effects of smoking on fetoplacental-maternal system during pregnancy. Am. J. Obstet. Gynecol. 149:413-420.

5. Jick, H., J. Porter, and A. S. Morrison. 1977. Relation between smoking and age of natural menopause. Lancet. i:1354-1355.

6. Willett, W., M. J. Stampfer, C. Bain, R. Lipnick, F. E. Speizer, B. Rosner, D. W. Cramer, and C. H. Hennekens. 1983. Cigarette smoking, relative weight and menopause. Am. J. Epidemiol. 117:651-658.

7. Daniell, H. W. 1976. Osteoporosis of the slender smoker. Arch. Intern. Med. 136:298-304.

8. Williams, A. R., N. S. Weiss, C. L. Ure, J. Ballard, and J. R. Daling. 1982. Effect of weight, smoking and estrogen use on the risk of hip and forearm fractures in postmenopausal women. Obstet. Gynecol. 60:695-699.

9. Patillo, R. A., A. Ruckert, R. Hussa, R. Bernstein, and E. Delfs. 1971. The Jar cell line: continuous human multihormone production and controls. In Vitro. 6:398-405.

10. Challis, J. R. G., I. J. Davies, and K. J. Ryan. 1973. The concentrations of progesterone, estrone and estradiol in the plasma of pregnant rabbits. Endocrinology. 93:971-976.

11. Challis, J. R. G., I. J. Davies, K. Benirschke, A. G. Hendrickx, and K. J. Ryan. 1975. The effects of dexamethasone on the peripheral plasma concentrations of androstenedione, testosterone and cortisol in the pregnant rhesus monkey. Endocrinology. 96:185-192.

12. Canick, J. A., and K. J. Ryan. 1976. Cytochrome P-450 and the aromatization of $16 \alpha$-hydroxytestosterone and androstenedione by human placental microsomes. Mol. Cell. Endocrinol. 6:105-115.

13. Bradford, M. M. 1976. Rapid and sensitive method for quantitation of microgram quantities of protein utilizing principle of proteindye banding. Anal. Biochem. 72:248-254.

14. Gore-Langton, R. E., and J. H. Dorrington. 1981. FSH induction of aromatase in cultured rat granulosa cells measured by a radiometric assay. Mol. Cell. Endocrinol. 22:135-141.

15. Barbieri, R. L., J. A. Canick, and K. J. Ryan. 1977. Danazol inhibits steroidogenesis in the rat testes in vitro. Endocrinology. 101: 1676-1682.

16. Kew, R. R., B. Ghebrehiwet, and A. Janoff. 1985. Cigarette smoke can activate the alternative pathway of complement in vitro by modifying the third component of complement. J. Clin. Invest. 75:1000-1007.

17. Barbieri, R. L., J. A. Canick, and K. J. Ryan. 1981. High-affinity steroid binding to rat testis $17 \alpha$-hydroxylase and human placental aromatase. J. Steroid Biochem. 14:387-393.

18. Estabrook, R. W., J. Peterson, J. Baron, and A. Hildebrant. 1972. A spectrometric measurement of turbid suspensions of cytochromes associated with drug metabolism. In Methods in Pharmacology, Vol. II. C. F. Chignell, editor. Appleton Century Crofts, NY. 303-350.

19. Meldrum, D. R., B. J. Davidson, I. V. Tataryn, and H. L. Judd. 1981. Changes in steroids with aging in postmenopausal women. Obstet. Gynecol. 57:624-628.

20. Graves, P. E., and H. A. Salhanick. 1979. Stereoselective inhibition of aromatase by enantiomers of aminoglutethimide. Endocrinology. 105: $52-57$.

21. Kellis, J. T., and L. E. Vickery. 1984. Inhibition of human estrogen synthetase (aromatase) by flavones. Science (Wash. DC). 225:1032-1034.

22. Russell, M. A. H., C. Wilson, U. A. Patel, C. Feyerabend, and P. V. Cole. 1975. Plasma nicotine levels after smoking cigarettes with high, medium and low nicotine yields. Br. Med. J. 2:414-416.

23. Benowitz, N. L., S. M. Hall, R. I. Herning, P. Jacob, R. T. Jones, and A. L. Osman. 1983. Smokers of low-yield cigarettes do not consume less nicotine. N. Engl. J. Med. 309:139-142.

24. Herning, R. I., R. T. Jones, N. L. Benowitz, and A. H. Mines. 1983. How a cigarette is smoked determines blood nicotine levels. Clin. Pharmacol. Ther. 33:84-90.

25. Russell, M. A. H., and C. Feyerabend. 1978. Cigarette smoking: a dependence on high-nicotine boli. Drug Metab. Rev. 8:29-57.

26. Sasson, I. M., N. J. Haley, D. Hoffman, E. L. Wynder, D. Hellberg, and S. Nilsson. 1985. Cigarette smoking and neoplasia of the uterine cervix: smoke constituents in cervical mucus. N. Engl. J. Med. 312:315316.

27. Ishiyama, I., T. Nagai, and S. Toshida. 1983. Detection of basic drugs from human hair. J. Forensic Sci. 28:380-385.

28. Haley, N. J., and D. Hoffman. 1985. Analysis for nicotine and cotinine in hair to determine cigarette smoker status. Clin. Chem. 31: 1598-1600.

29. Goodman, A. L., and G. D. Hodgen. 1983. The ovarian triad of the primate menstrual cycle. Recent Prog. Horm. Res. 39:1-73.

30. McNatty, K. P., D. M. Smith, A. Makris, R. Osathanondh, and K. J. Ryan. 1979. The microenvironment of the human antral follicle: interrelationships among the steroid levels in antral fluid, the population of granulosa cells, and the status of the oocyte in vivo and in vitro. $J$. Clin. Endocrinol. Metab. 49:851-860.

31. Jensen, J., C. Christiansen, and P. Rodbro. 1985. Cigarette smoking, serum estrogens and bone loss during hormone-replacement therapy early after menopause. $N$. Engl. J. Med. 313:973-975. 